\title{
Dental-derived stem cells and biowaste biomaterials: What's next in bone regenerative medicine applications
}

\author{
Michele Di COSOlA ${ }^{1, \$}$; Stefania CANTORE ${ }^{2, \$, *}$; Mario Giosuè BalZanelli ${ }^{3}$; Ciro Gargiulo ISACCO ${ }^{2,3}$; Kieu Cao \\ Diem NGUYEN ${ }^{2,3}$; RaJiv SAINI ${ }^{2}$; ANNARITA MALCANGI ${ }^{4}$; MARGHERITA TUMEDEI ${ }^{5}$; MaRIaTERESA AMBROSINO ${ }^{1}$; \\ ANTONIO MANCINI ${ }^{2}$; SALVATORE SCACCO ${ }^{6}$; RiCCARDo NOCINI ${ }^{7}$; LUIGI SANTACROCE ${ }^{2}$; ANDREA BALLINI ${ }^{8,9, \#, * ;}$ \\ EDOARDO BRAUNER ${ }^{10, \#}$ \\ ${ }^{1}$ Department of Clinical and Experimental Medicine, Università degli Studi di Foggia, Foggia, 71122, Italy \\ 2 Department Interdisciplinary of Medicine, University of Bari “Aldo Moro", Bari, 70124, Italy \\ 3 SET-118, Department of Pre-Hospital and Emergency, SG Giuseppe Moscati Hospital, Taranto, 74010, Italy \\ 4 Azienda Sanitaria Locale BAT, Trani, 76125, Italy \\ ${ }^{5}$ Department of Medical, Oral and Biotechnological Sciences, University of Chieti, Chieti, 66100, Italy \\ 6 Department of Basic Medical Sciences, Neuroscience and Sense Organs, University of Bari "Aldo Moro", Bari, 70124, Italy \\ 7 Department of Surgical Sciences, Dentistry, Gynecology and Pediatric, University of Verona, Verona, 37126, Italy \\ ${ }^{8}$ School of Medicine, University of Bari “Aldo Moro", Bari, 70124, Italy \\ 9 Department of Precision Medicine, University of Campania "Luigi Vanvitelli”, Naples, 80138, Italy \\ ${ }^{10}$ Department of Oral and Maxillo-Facial Sciences, Sapienza University of Rome, Roma, 00161, Italy
}

Key words: Dental-derived stem cells, Secretome, Biomaterials, Bone regenerative medicine, Waste medicine

\begin{abstract}
The human teeth and oral cavity harbor various populations of mesenchymal stem cells (MSCs), so called dental-derived stem cells (D-dSCs) with self-renewing and multilineage differentiation capabilities. D-dSCs properties involves a strong paracrine component resulting from the high levels of bioactive molecules they secrete in response to the local microenvironment. Altogether, this viewpoint develops a general picture of current innovative strategies to employ D-dSCs combined with biomaterials and bioactive factors for regenerative medicine purposes, and offers information regarding the available scientific data and possible applications.
\end{abstract}

\section{Introduction}

Mesenchymal stem cells (MSCs) are undifferentiated high proliferative cells, well known for their self-renewal and differentiation properties in multiple cell lines, in response to the microenvironmental conditions in which they grown (Charitos et al., 2021).

The International Society for Cellular Therapy (ISCT) in 2005 had established benchmarks for defining MSCs with the following minimal criteria: (a) must be plastic-adherent and fibroblastoid under standard culture conditions (b) must display immunophenotypic expression of CD73, CD90, CD105 and a lack of expression of CD34, CD45, CD14,

*Address correspondence to: Andrea Ballini, andrea.ballini@me.com; Stefania Cantore, stefaniacantore@pec.omceo.bari.it

${ }^{\S}$ Contributed equally as co-first authors

${ }^{\#}$ Contributed equally as co-last authors

Received: 06 August 2021; Accepted: 23 September 2021
CD19, CD79a, CD31 and HLA-DR surface markers (c) and lastly, (d) must have the capacity to minimally differentiate into adipocytes, osteocytes, and chondroblasts in vitro (Horwitz et al., 2005; Praveen Kumar et al., 2019).

MSCs are also able to produce immunomodulatory factors, leading to the creation of a regenerative microenvironment. Thanks to these properties, MSCs may play a main role in regenerative medicine, and some clinical studies have demonstrated that MSCs from different sources may have the ability to repair injured tissues, such as bone (Salgado et al., 2020; Gugliandolo et al., 2021) and corneal tissue engineering (Nosrati et al., 2021a), wound healing and muscle (Martínez-Sarrà et al., 2017), cartilage regeneration (Mata et al., 2017; Dang et al., 2021), as well spinal cord injuries (Asadi-Golshan et al., 2021).

To gather the rising demand for human tissues and organs since of diseases or accidents, scientific research is progressively more focusing on tissue engineering and regenerative medicine. The core common methods of set up 
tissues and organs are (I) the addition of bioscaffolds, growth factors, and MSCs into a culture medium for in vitro organization and (II) the implantation of bioscaffolds and growth factors for in vivo organization (Wang et al., 2020). Comparable to the natural extracellular matrix (ECM), topography, morphology and composition of scaffold manage cell behavior, showing influence on cell adhesion, proliferation, differentiation and migration.

Consequently materials structure, architecture and composition should reproduce the native extracellular matrix (ECM) as more strict as it is possible to entirely mimic target tissue environment. Besides, scaffolds should be immunologically inert or influence minimal immunological reaction (Litowczenko et al., 2021; Boccaccio et al., 2018).

In general, the present viewpoint develops a general overview of current innovative strategies to (I) employ DdSCs combined with biological waste biomaterials, from renewable and biodegradable bioactive compounds, to obtain new materials having lower cost and comparable properties, for bone regenerative medicine purposes, and (II) offers information regarding the available scientific data and possible applications of D-dSCs use.

Following this approach, biowaste could be considered as a high value resource which could be converted into sustainable materials and new active factors fully complying with the circular economy concept.

\section{Dental-derived stem cells (D-dSCs)}

In the early begin of the current millennium, moved by the isolation of MSCs from bone marrow (BMSCs), stem cells form oral tissues were firstly isolated from dental pulp (DPSCs).

During the last 20 years, the concept of Dental-derived stem cells (D-dSCs), was associated to a specific kind of MSCs, obtained by specific methods, i.e., separating tissues around human teeth (Figs. 1A and 1B).

So far, nine types of dental stem cells were successfully isolated, including DPSCs, stem cells from human exfoliated deciduous teeth (SHEDs), apical papilla stem cells (SCAPs), periodontal ligament stem cells (PDLSCs), dental follicle stem cells (DFSCs), gingival mesenchymal stem cells (GMSCs), human tooth germ stem cells (TGPCs), alveolar bone mesenchymal stem cells (ABMSCs) and human periapical cyst mesenchymal stem cells (hPCy-MSCs), as well reported in scientific literature (Lei et al., 2021; Paduano et al., 2016, Ballini et al., 2007a; Cantore et al., 2018; Ballini et al., 2015; Mason et al., 2014).

During development of the maxilla and mandible, neural crest cells (NCCs) delaminate from the neural tube and migrate towards the maxillary and mandibular primordia (Blentic et al., 2008) where interact with local tissue and initiate a differentiation process that gives rise to ectomesenchymal derivatives express several factors which play an important role during the differentiation of bone, cartilage, and teeth (da Silva Sasso et al., 2021).

Moreover, some explorative studies, showed the differential expression of pro-angiogenic factors for D-dSCs by suggesting this MSCs populations could act as scaffolds, potentially promote the vascularization of hard (Hilkens et al., 2014) and soft (Nosrati et al., 2021b) tissues. Since oral tissues develop from migrating cranial cells, dental-derived MSCs display ready availability and high proliferation abilities (Chen et al., 2021; Wang and Cao, 2019; Zhang et al., 2019; Matsui et al., 2018; Carnevale et al., 2018; Inada et al., 2017; Huang et al., 2017; Aguilar and Lertchirakarn, 2016; Pan et al., 2016).

Apart from their direct cellular activity following stem/ progenitor cells engraftment, D-dSCs/MSCs mark on regenerative medicine is indirectly mediated through paracrine effects (El Moshy et al., 2020). In fact, throughout the release of trophic and modulatory bioactive factors (secretome) into the surrounding environment, they can influence tissue homeostasis, can stimulate cellular migration, proliferation, immunomodulation and promote tissue regeneration (El Moshy et al., 2020).

In addition D-dSCs exhibit peculiar advantages first of all, for the easy accessible localization, compared to other sites (i.e., iliac crest), and secondly for using post-natal tissues (by-passing ethic concerns), of samples that most of the time are extracted for clinical issues (i.e., orthodontics reasons, impacted teeth, etc), becoming in this way a biowaste specimen ready to use in wider circular economy concept.

The DPSCs, SHEDs, SCAPs and ABMSCs, posses the advantages of potential clinical applications in the field of angiogenesis and/or dental/pulp complex formation, as well PDLSCs and DFSCs show features for periodontal
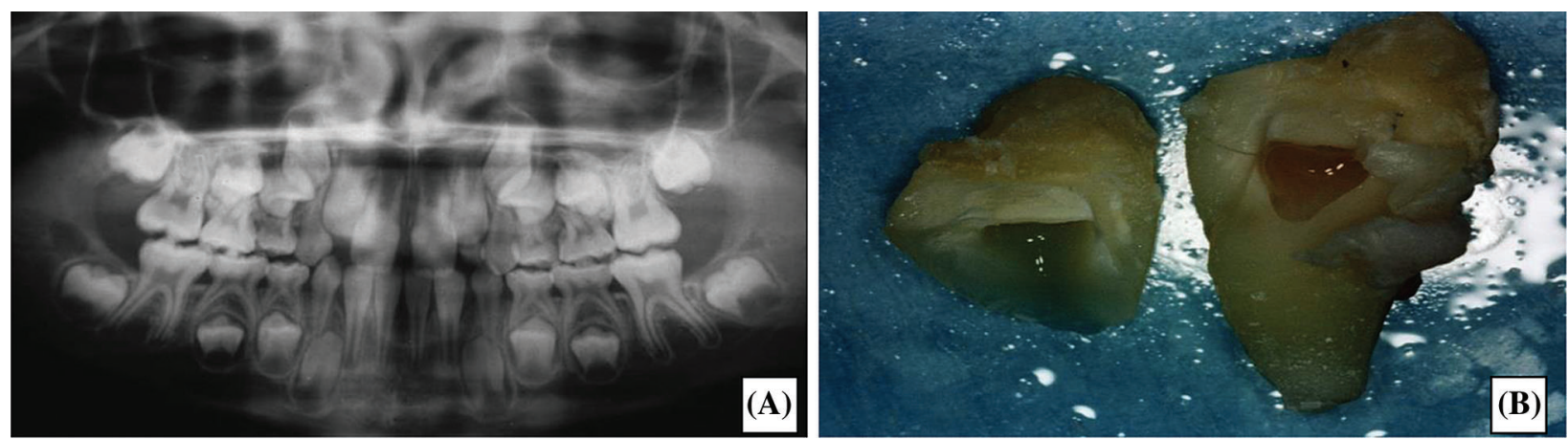

FIGURE 1. Clinical Images. (A) Orthopantomogram of different MSCs sources: immature dental tissues follicle/germ (DFSCs/SCAPs/ TGPCs), Dental Molars (DPSCs), Deciduous Teeth (SHEDs) and alveolar bone (ABMSCs). (B) After the cut, the pulp chamber and its content were revealed. The tooth pulp provided DPSCs. For clinical images, written and verbal information was given to the patient before the procedure, and written informed consent was obtained, in full accordance with the World Medical Association Declaration of Helsinki on experimentation involving human subjects, as revised in 2008. 
tissue regeneration (Chen et al., 2021; Mason et al., 2014; Ballini et al., 2007b).

On the other hand, GMSCs, TGPCs and hPCy-MSCs seems to demonstrate potential applications in nerve regeneration (Chen et al., 2021; Paduano et al., 2016) (Table 1).

The limitation reported in literature, in general for all type of MSCs, included the D-dSCs family, are most of the time limited to the specimen collection contamination, culture conditions/passages, and dependent for the specific clinical purpose as well the safety issues (Lee, 2018; Ballini et al., 2017).

Current perspectives in regenerative medicine applications The similarity of gene expression profiles between D-dSCs, osteoblast precursors and BMSCs has recently been reported, as well their stemness properties (Posa et al., 2021; Cantore et al. 2017; Ballini et al., 2017; Mori et al., 2010). In fact D-dSCs have revealed the expression of transcription factors like kruppel-like factor 4 (Klf4), octamer-binding transcription factor 4 (OCT4), homeobox transcription factor Nanog (Nanog), v-myc avian myelocytomatosis viral oncogene homolog (c-Myc), and SRY (sex determining region Y)-box 2 (Sox2), that plays a key regulatory activity in the stem cell self-renewal process in replenishing mature cells that constantly die due to normal and constant tissue turnover reprogramming (Ballini et al., 2019). In this light, Takahashi and Yamanaka showed in 2006 (Charitos et al., 2021) that the introduction of specific genes encoding transcription factors such as OCT4, Nanog, Klf4, c-Myc and Sox2 in keeping the pluripotency status of stem cells has been well confirmed either in embryonic stem cells (ESCs) or in induced pluripotent stem cells (iPS), keeping them in a stemness state preventing their differentiation, and sustaining their self-renewal.

The term "tissue engineering" identifies tissue regeneration procedures of the human organism through the seeding of cells on structures (scaffolds) made up of specific materials and with peculiar characteristics, their cultivation in special reactors (bioreactors) until the colonization of the same scaffold, and to the neo-formation of a bioengineered tissue (Bettini et al., 2020; Cantore et al., 2018; Nosrati et al., 2020). The recent trend is the scaffolds creation for the in vitro genesis of bio-tissues (Wang et al., 2020); in this case, bioabsorbable polymeric materials used in $3 \mathrm{D}$ printers are employed, generally with fused deposition modeling (FDM) techniques (filament extrusion) or with bioprinting (nozzles that spray small amounts of liquid material). In studies on animal models, some authors have tested the isolation and use of D-dSCs and bio-scaffolds for bone regeneration, obtaining neo-formation of bone tissue in the grafted sites (Shoushrah et al., 2021).

Bio-scaffolds material properties in bone regeneration are a key factor for maximizing cell recruitment and differentiation and to minimize local induced inflammatory response after in situ implantation. Such materials are selected according to the following characteristics: (i) ability to provide appropriate mechanical support to the tissue, (ii) ability to determine the digestibility of the scaffold, and (iii) proficiency to trigger the appropriate immune response to promote tissue regeneration and healing (Li et al., 2019). In this light, is possible that natural biomaterials can control macrophage activation and lower the foreign body reaction mediating constant cross-talk with inflammatory cells (Li et al., 2019; Swartzlander et al., 2015).

Currently, still if in the pioneering phase, there is the use of polyphenols in the regeneration of bone tissue. In particular, has been investigated that, the oligostylbenes (natural compounds) deriving from the recovery of waste of agri-food processes (waste compounds), in association with D-dSCs/MSCs, can promote the early consolidation and mineralization of bioengineered tissue with a significant decrease in the healing time (Di Benedetto et al., 2018; Murgia et al., 2019; Posa et al., 2020). Preliminary experiments have shown an increased deposition of mineralized matrix in osteoblastic differentiated MSCs in

TABLE 1

\section{Main D-dSCs markers and related functions}

\begin{tabular}{|c|c|c|}
\hline Marker & Function & References \\
\hline CD146 & $\begin{array}{l}\text { Cell adhesion molecule and an integral membrane glycoprotein at the intercellular } \\
\text { junction }\end{array}$ & Matsui et al. (2018) \\
\hline $\begin{array}{l}\mathrm{CD} 271 \text { or } \mathrm{p} 75 \\
\text { neurotrophin receptor } \\
(\mathrm{NTR})\end{array}$ & $\begin{array}{l}\text { Well-conserved transmembrane pro-neurotrophin/neurotrophin receptor that plays } \\
\text { critical roles in the maintenance of nerve cell viability and in tooth development and } \\
\text { epithelial-mesenchymal transition (EMT). }\end{array}$ & Pan et al. (2016) \\
\hline STRO-1 & $\begin{array}{l}\text { Marker that recognizes a trypsin-insensitive epitope on perivascular cells, and has } \\
\text { shown enhanced proliferation potential }\end{array}$ & $\begin{array}{l}\text { Carnevale et al. } \\
\text { (2018) }\end{array}$ \\
\hline $\begin{array}{l}\text { Alkaline phosphatase } \\
\text { (ALP) }\end{array}$ & $\begin{array}{l}\text { Expressed in undifferentiated cells. ALP is also a marker of neuronal progenitor cells, } \\
\text { human myogenic progenitor cells (also called "pericytes"), and BMMSCs }\end{array}$ & Inada et al. (2017) \\
\hline Nuclear factor I-C (NFIC) & Key regulator of tooth development & Zhang et al. (2019) \\
\hline $\begin{array}{l}\text { Wnt inhibitory factor } 1 \\
\text { (WIF1) }\end{array}$ & Enhance the dentinogenic differentiation potential in SCAPs via its regulation of OSX & $\begin{array}{l}\text { Wang and Cao } \\
(2019)\end{array}$ \\
\hline $\mathrm{CD} 39$ and $\mathrm{CD} 73$ & $\begin{array}{l}\text { CD39 and CD73 are coexpressed on GMSCs and regulate T cells, which play a catalytic } \\
\text { role to promote immune regulation and reduce inflammation }\end{array}$ & Huang et al. (2017) \\
\hline $\mathrm{CD} 24$ & Specific surface marker, which can distinguish SCAP from DPSCs and BMSCs & $\begin{array}{l}\text { Aguilar and } \\
\text { Lertchirakarn } \\
(2016)\end{array}$ \\
\hline
\end{tabular}




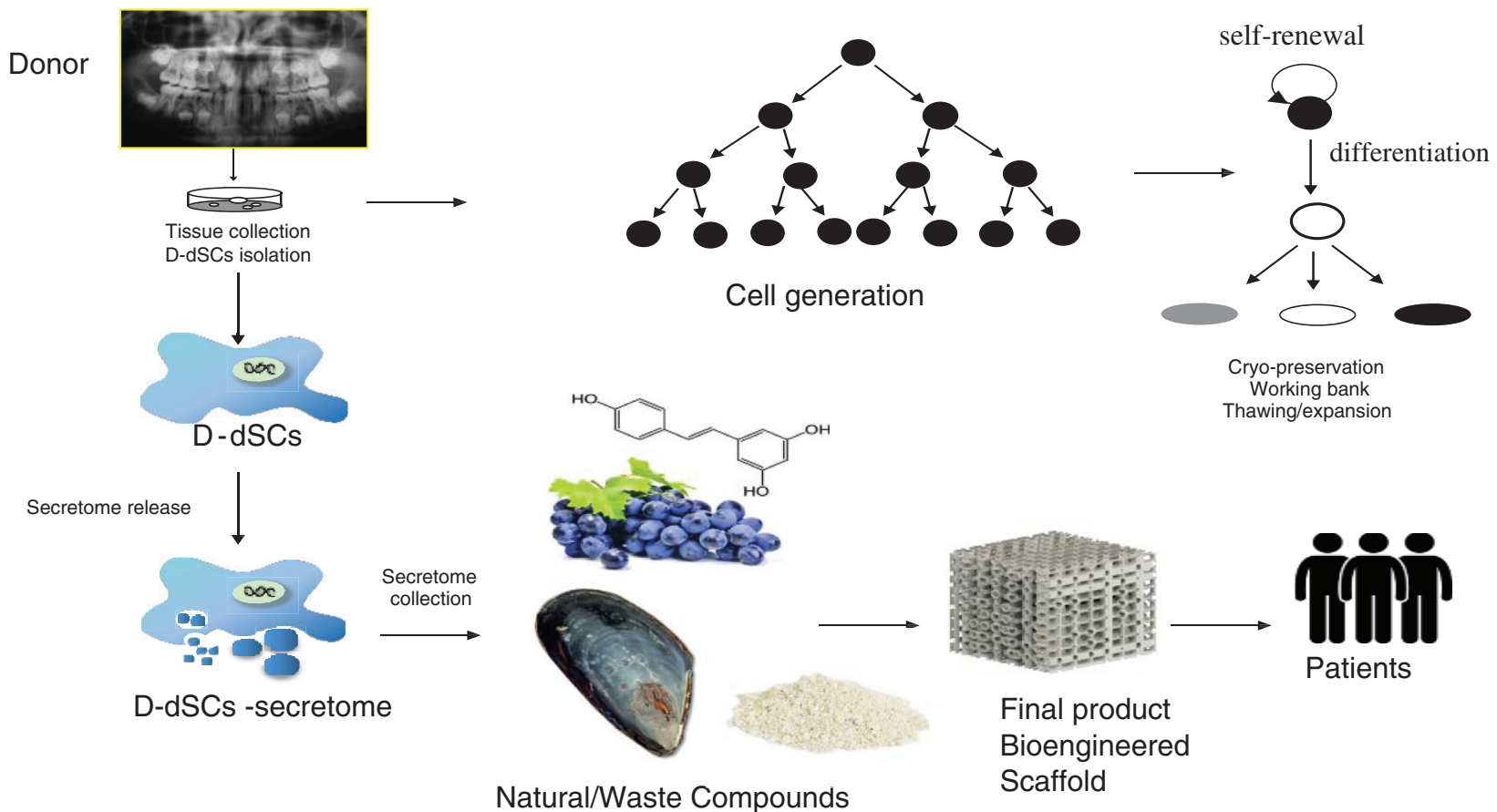

FIGURE 2. From waste to regenerative medicine: biotechnological applications of D-dSCs in the context of innovative sustainability and circular economy.

presence of natural compounds/waste compounds of agrifood origin, as well as potential antioxidant, anti-aging and anti-tumor capacities have been documented (di Benedetto et al., 2018; Di Domenico et al., 2020). These biological characteristics could have an impact on the immunomodulatory and therapeutic potentials of D-dSCs in vivo since, in the implantation phase, the contact of the stem cells with the bacteria through the Toll-like receptors (TLRs), triggers the activation of an inflammatory response inducing vascularization and osteogenesis (Fehrmann et al., 2020). To date, it has been shown that the TLRs expression pattern could influence the therapeutic potential of adult MSCs during in vivo transplantation (Fehrmann et al., 2020; Fawzy El-Sayed et al., 2017).

Consequently, it is possible to speculate that the intrinsic antibacterial, anti-inflammatory and antioxidant activity of natural compounds/waste compounds could be inhibitory on the production of pro-inflammatory molecules, in the maintenance phase of a bio-scaffold loaded with D-dSCs in vivo interacting, in a positive way, with the oral microbiota (Vázquez et al., 2020). Furthermore, in the literature are reported in vitro studies about the realization of scaffolds deriving from a mixture of organic compounds included in some easily available waste compounds, such as egg shells or mussels (Mytilus edulis), useful for the recovery of calcium phosphates in the form of hydroxyapatite (HA), hair keratin (improvement of scaffold properties by cell adhesion), and jellyfish, rich in bioactive compounds (collagen) already used in nutraceuticals and cosmeceuticals (Scialla et al., 2020; Arslan et al., 2017). The bioscaffold obtained according to the principles of the circular economy, can be additionally soaked with polyphenols (strengthening osteogenic and osteoinductive effects, antiinflammatory, antibacterial and antioxidant properties) thanks to diatomaceous flour, which also act to consolidates the scaffold's mechanical properties (Bonifacio et al., 2020) (Fig. 2).

\section{Current limitations}

While the preclinical evidence showing the regenerative and immunomodulatory potential of the D-dSCs/MSCs secretome continues to expand rapidly, the clinical studies revolving around this hypothesis are still scarce (Ferreira et al., 2018). Even if D-dSCs/MSCs have an innate potential to induce and/or contribute to regeneration, this potential is now known to be greatly influenced by diverse extrinsic factors such as the tissue source of the D-dSCs/MSCs, the health status and age of the MSCs donor, the batch/lot of serum used for the in vitro culture of the D-dSCs/MSCs, passage number, oxygen concentration (Ferreira et al., 2018), and in general for cell culture, the presence/absence of a pro-inflammatory, apoptotic or genotoxic environment when the cells are infused (Mori et al., 2009; Ferreira et al., 2018; Mori et al., 2007; Lovreglio et al., 2006). The success of D-dSCs/MSC transplantation relates to large scale in vitro expansion of therapeutically qualified cells under Good Manufacturing Practice (GMP) conditions, although a standard therapeutic cell dose of D-dSCs/MSCs, the route of administration and the number of doses are still being optimized. Although culture expansion of D-dSCs/MSCs has been widely used, a few issues need to be highlighted (Praveen Kumar et al., 2019; Ballini et al., 2018).

\section{Conclusions}

Dental-derived stem cells are today considered as an intriguing milestone of the regenerative medicine. In summary, an advanced understanding of the interactions among D-dSCs/ MSCs, immune cells, and biomaterials and natural compounds that modulate immunoregulation and response to inflammation could be translated into the development of advanced biomaterials and change the way that experts approach tissue regeneration. Such advancements can open 
new horizons toward more efficient personalized therapies and optimized clinical outcomes. Starting from the contents of the present viewpoint, the scientific community will be stimulated to experiment new ideas, to improve the knowledge of D-dSCs, and to speed up their clinical application, so to improve regenerative medicine approaches.

Authors' Contribution: The authors confirm contribution to the paper as follows: study design: all the authors; data collection: all the authors; analysis and interpretation of results: all the authors; draft manuscript preparation: M.D. C., S.C., A.B., and E.B. Conceptualization and final validation A.B., M.D.C. and S.C. Finally M.D.C. and S.C. equally contributed as co-first authors and E.B. and A.B. as co-last authors. All authors reviewed the results and approved the final version of the manuscript.

Funding Statement: The authors received no specific funding for this study.

Conflicts of Interest: The authors declare that they have no conflicts of interest to report regarding the present study.

\section{References}

Aguilar P, Lertchirakarn V (2016). Comparison of stem cell behaviors between indigenous high and low-CD24 percentage expressing cells of stem cells from apical papilla (SCAPs). Tissue \& Cell 48: 397-406.

Arslan YE, Arslan YE, Sezgin Arslan T, Derkus B, Emregul E, Emregul KC (2017). Fabrication of human hair keratin/jellyfish collagen/ eggshell-derived hydroxyapatite osteoinductive biocomposite scaffolds for bone tissue engineering: From waste to regenerative medicine products. Colloids and Surfaces B, Biointerfaces 154: 160-170.

Asadi-Golshan R, Razban V, Mirzaei E, Rahmanian A, Khajeh S, Mostafavi-Pour Z, Dehghani F (2021). Efficacy of dental pulp-derived stem cells conditioned medium loaded in collagen hydrogel in spinal cord injury in rats: Stereological evidence. Journal of Chemical Neuroanatomy 116: 101978.

Ballini A, De Frenza G, Cantore S, Papa F, Grano M, Mastrangelo F, Tetè S, Grassi FR (2007a). In vitro stem cell cultures from human dental pulp and periodontal ligament: New prospects in dentistry. International Journal of Immunopathology and Pharmacology 20: 9-16.

Ballini A, Capodiferro S, Toia M, Cantore S, Favia G, De Frenza G, Grassi FR (2007b). Evidence-based dentistry: What's new? International Journal of Medical Sciences 4: 174-178.

Ballini A, Mastrangelo F, Gastaldi G, Tettamanti L, Bukvic N et al. (2015). Osteogenic differentiation and gene expression of dental pulp stem cells under low-level laser irradiation: A good promise for tissue engineering. Journal of Biological Regulators and Homeostatic Agents 29: 813-822.

Ballini A, Boccaccio A, Saini R, van Pham P, Tatullo M (2017). Dental-derived stem cells and their secretome and interactions with bioscaffolds/biomaterials in regenerative medicine: From the in vitro research to translational applications. Stem Cells International 2017: 6975251.

Ballini A, Cantore S, Scacco S, Coletti D, Tatullo M (2018). Mesenchymal stem cells as promoters, enhancers, and playmakers of the translational regenerative medicine 2018 . Stem Cells International 2018: 6927401.
Ballini A, Di Benedetto A, de Vito D, Scarano A, Scacco S et al. (2019). Stemness genes expression in naïve vs. osteodifferentiated human dental-derived stem cells. European Review for Medical and Pharmacological Sciences 23: 2916-2923.

Bettini S, Bonfrate V, Valli L, Giancane G (2020). Paramagnetic functionalization of biocompatible scaffolds for biomedical applications: A perspective. Bioengineering 7: 153.

Blentic A, Tandon P, Payto S, Walshe J, Carney T, Kelsh RN, Mason I, Graham A (2008). The emergence of ectomesenchyme. Developmental Dynamics 237: 592-601.

Boccaccio A, Uva AE, Fiorentino M, Monno G, Ballini A, Desiate A (2018). Optimal load for bone tissue scaffolds with an assigned geometry. International Journal of Medical Sciences 15: 16-22. DOI 10.7150/ijms.20522.

Bonifacio MA, Cochis A, Cometa S, Gentile P, Scalzone A, Scalia AC, Rimondini L, de Giglio E (2020). From the sea to the bee: Gellan gum-honey-diatom composite to deliver resveratrol for cartilage regeneration under oxidative stress conditions. Carbohydrate Polymers 245: 116410. DOI 10.1016/j. carbpol.2020.116410.

Cantore S, Ballini A, de Vito D, Martelli FS, Georgakopoulos I et al. (2017). Characterization of human apical papilla-derived stem cells. Journal of Biological Regulators and Homeostatic Agents 31: 901-910.

Cantore S, Crincoli V, Boccaccio A, Uva AE, Fiorentino M et al. (2018). Recent advances in endocrine, metabolic and immune disorders: Mesenchymal stem cells (MSCs) and engineered scaffolds. Endocrine, Metabolic \& Immune Disorders Drug Targets 5: 466-469. DOI 10.2174/ 1871530318666180423102905.

Carnevale G, Pisciotta A, Riccio M, Bertoni L, de Biasi S et al. (2018). Human dental pulp stem cells expressing STRO-1, c-kit and CD34 markers in peripheral nerve regeneration. Journal of Tissue Engineering and Regenerative Medicine 12: e774e785. DOI 10.1002/term.2378.

Charitos IA, Ballini A, Cantore S, Boccellino M, Di Domenico M, Borsani E, Nocini R, Di Cosola M, Santacroce L, Bottalico L (2021). Stem cells: A historical review about biological, religious, and ethical issues. Stem Cells International 2021: 9978837.

Chen J, Zheng X, Rao N, Huang Y, Liu J et al. (2021). Key markers and epigenetic modifications of dental-derived mesenchymal stromal cells. Stem Cells International 2021: 5521715.

da Silva Sasso GR, Florencio-Silva R, Sasso-Cerri E, Gil CD, de Jesus Simões M, Cerri PS (2021). Spatio-temporal immunolocalization of VEGF-A, Runx2, and osterix during the early steps of intramembranous ossification of the alveolar process in rat embryos. Developmental Biology 478: 133-143. DOI 10.1016/j.ydbio.2021.07.001.

Dang QT, Huynh TD, Inchingolo F, Dipalma G, Inchingolo AD et al. (2021). Human chondrocytes from human adipose tissuederived mesenchymal stem cells seeded on a dermalderived collagen matrix sheet: Our preliminary results for a ready to go biotechnological cartilage. Stem Cells International 2021: 6664697.

Di Benedetto A, Posa F, de Maria S, Ravagnan G, Ballini A, Porro C, Trotta T, Grano M, Muzio LL, Mori G (2018). Polydatin, natural precursor of resveratrol, promotes osteogenic differentiation of mesenchymal stem cells. International Journal of Medical Sciences 15: 944-952. DOI 10.7150/ijms.24111.

Di Domenico M, Feola A, Ambrosio P, Pinto F, Galasso G et al. (2020). Antioxidant effect of beer polyphenols and their bioavailability in dental-derived stem cells (D-dSCs) and 
human intestinal epithelial lines (Caco-2) cells. Stem Cells International 2020: 8835813.

El Moshy S, Radwan IA, Rady D, Abbass MMS, El-Rashidy AA, Sadek KM, Dörfer CE, Fawzy El-Sayed KM (2020). Dental stem cell-derived secretome/conditioned medium: The future for regenerative therapeutic applications. Stem Cells International 2020: 1-29. DOI 10.1155/2020/7593402.

Fawzy El-Sayed KM, Boeckler J, Dörfer CE (2017). TLR expression profile of human alveolar bone proper-derived stem/ progenitor cells and osteoblasts. Journal of Cranio-MaxilloFacial Surgery 45: 2054-2060. DOI 10.1016/j.jcms.2017.09.007.

Fehrmann C, Dörfer CE, Fawzy El-Sayed KM (2020). Toll-like receptor expression profile of human stem/progenitor cells form the apical papilla. Journal of Endodontics 46: 16231630. DOI 10.1016/j.joen.2020.08.017.

Ferreira JR, Teixeira GQ, Santos SG, Barbosa MA, Almeida-Porada G, Gonçalves RM (2018). Mesenchymal stromal cell secretome: Influencing therapeutic potential by cellular preconditioning. Frontiers in Immunology 9: 2837. DOI 10.3389/fimmu.2018.02837.

Gugliandolo A, Fonticoli L, Trubiani O, Rajan TS, Marconi GD, Bramanti P, Mazzon E, Pizzicannella J, Diomede F (2021). Oral bone tissue regeneration: mesenchymal stem cells, secretome, and biomaterials. International Journal of Molecular Sciences 22: 5236.

Hilkens P, Fanton Y, Martens W, Gervois P, Struys T, Politis C, Lambrichts I, Bronckaers A (2014). Pro-angiogenic impact of dental stem cells in vitro and in vivo. Stem Cell Research 12: $778-790$.

Horwitz EM, Le Blanc K, Dominici M, Mueller I, Slaper-Cortenbach I et al. (2005). Clarification of the nomenclature for MSC: The international society for cellular therapy position statement. Cytotherapy 7: 393-395.

Huang F, Chen M, Chen W, Gu J, Yuan J et al. (2017). Human gingiva-derived mesenchymal stem cells inhibit xeno-graftversus-host disease via CD39-CD73-adenosine and IDO signals. Frontiers in Immunology 8: 68.

Inada E, Saitoh I, Kubota N, Soda M, Matsueda K, Murakami T, Sawami T, Kagoshima A, Yamasaki Y, Sato M (2017). Alkaline phosphatase and OCT-3/4 as useful markers for predicting susceptibility of human deciduous teeth-derived dental pulp cells to reprogramming factor-induced iPS cells. Journal of Investigative and Clinical Dentistry 8: 4.

Lee SH (2018). The advantages and limitations of mesenchymal stem cells in clinical application for treating human diseases. Osteoporosis and Sarcopenia 4: 150. DOI 10.1016/ j.afos.2018.11.083.

Lei T, Zhang X, Du H (2021). Characteristics, classification, and application of stem cells derived from human teeth. Stem Cells International 2021: 8886854.

Li H, Shen S, Fu H, Wang Z, Li X, Sui X, Yuan M, Liu S, Wang G, Guo $Q$ (2019). Immunomodulatory functions of mesenchymal stem cells in tissue engineering. Stem Cells International 2019: 1-18. DOI 10.1155/2019/9671206.

Litowczenko J, Woźniak-Budych MJ, Staszak K, Wieszczycka K, Jurga S, Tylkowski B (2021). Milestones and current achievements in development of multifunctional bioscaffolds for medical application. Bioactive Materials 6: 2412-2438. DOI 10.1016/j.bioactmat.2021.01.007.

Lovreglio P, Bukvic N, Fustinoni S, Ballini A, Drago I, Foà V, Guanti G, Soleo L (2006). Lack of genotoxic effect in workers exposed to very low doses of 1,3-butadiene. Archives of Toxicology 80: 378-381. DOI 10.1007/s00204-005-0046-0.

Martínez-Sarrà E, Montori S, Gil-Recio C, Núñez-Toldrà R, Costamagna D, Rotini A, Atari M, Luttun A, Sampaolesi M (2017). Human dental pulp pluripotent-like stem cells promote wound healing and muscle regeneration. Stem Cell Research and Therapy 8: 175.

Mason S, Tarle SA, Osibin W, Kinfu Y, Kaigler D (2014). Standardization and safety of alveolar bone-derived stem cell isolation. Journal of Dental Research 93: 55-61.

Mata M, Milian L, Oliver M, Zurriaga J, Sancho-Tello M, de Llano JJM, Carda C (2017). In vivo articular cartilage regeneration using human dental pulp stem cells cultured in an alginate scaffold: A preliminary study. Stem Cells International 2017: 8309256.

Matsui M, Kobayashi T, Tsutsui TW (2018). CD146 positive human dental pulp stem cells promote regeneration of dentin/pulplike structures. Human Cell 31: 127-138.

Murgia D, Mauceri R, Campisi G, de Caro V (2019). Advance on resveratrol application in bone regeneration: Progress and perspectives for use in oral and maxillofacial surgery. Biomolecules 9: 94.

Mori G, Centonze M, Brunetti G, Ballini A, Oranger A et al. (2010). Osteogenic properties of human dental pulp stem cells. Journal of Biological Regulators and Homeostatic Agents 24: 167-175.

Mori G, Brunetti G, Colucci S, Oranger A, Ciccolella F et al. (2009). Osteoblast apoptosis in periodontal disease: Role of TNFrelated apoptosis-inducing ligand. International Journal of Immunopathology and Pharmacology 22: 95-103. DOI 10.1177/039463200902200111.

Mori G, Brunetti G, Colucci S, Ciccolella F, Coricciati M et al. (2007). Alteration of activity and survival of osteoblasts obtained from human periodontitis patients: Role of TRAIL. Journal of Biological Regulators and Homeostatic Agents 21: 105-114.

Nosrati H, Alizadeh Z, Nosrati A, Ashrafi-Dehkordi K, BanitalebiDehkordi M, Sanami S, Khodaei M (2021a). Stem cellbased therapeutic strategies for corneal epithelium regeneration. Tissue \& Cell 68: 101470. DOI 10.1016/j. tice.2020.101470.

Nosrati H, Aramideh Khouy R, Nosrati A, Khodaei M, BanitalebiDehkordi M, Ashrafi-Dehkordi K, Sanami S, Alizadeh Z (2021b). Nanocomposite scaffolds for accelerating chronic wound healing by enhancing angiogenesis. Journal of Nanobiotechnology 19: 1. DOI 10.1186/s12951-020-00755-7.

Nosrati H, Abpeikar Z, Mahmoudian ZG, Zafari M, Majidi J, Alizadeh A, Moradi L, Asadpour S (2020). Corneal epithelium tissue engineering: Recent advances in regeneration and replacement of corneal surface. Regenerative Medicine 15: 2029-2044.

Pan W, Kremer KL, Kaidonis X, Ludlow VE, Rogers ML, Xie J, Proud CG, Koblar SA (2016). Characterization of p75 neurotrophin receptor expression in human dental pulp stem cells. International Journal of Developmental Neuroscience 53: 90-98. DOI 10.1016/j.ijdevneu.2016.07.007.

Paduano F, Marrelli M, Palmieri F, Tatullo M (2016). CD146 expression influences periapical cyst mesenchymal stem cell properties. Stem Cell Reviews and Reports 12: 592-603. DOI 10.1007/s12015-016-9674-4.

Praveen Kumar L, Kandoi S, Misra R, Verma RS (2019). The mesenchymal stem cell secretome: A new paradigm towards cell-free therapeutic mode in regenerative 
medicine. Cytokine \& Growth Factor Reviews 46: 1-9. DOI 10.1016/j.cytogfr.2019.04.002.

Posa F, Colaianni G, Di Cosola M, Dicarlo M, Gaccione F, Colucci S, Grano M, Mori G (2021). The myokine irisin promotes osteogenic differentiation of dental bud-derived MSCs. Biology (Basel) 10: 295.

Posa F, Di Benedetto A, Ravagnan G, Cavalcanti-Adam EA, Lo Muzio L, Percoco G, Mori G (2020). Bioengineering bone tissue with $3 \mathrm{D}$ printed scaffolds in the presence of oligostilbenes. Materials 13: 4471. DOI 10.3390/ ma13204471.

Salgado CL, Barrias CC, Monteiro FJM (2020). Clarifying the toothderived stem cells behavior in a $3 \mathrm{D}$ biomimetic scaffold for bone tissue engineering applications. Frontiers in Bioengeering and Biotechnology 8: 724. DOI 10.3389/ fbioe.2020.00724.

Scialla S, Carella F, Dapporto M, Sprio S, Piancastelli A, Palazzo B, Adamiano A, Degli Esposti L, Iafisco M, Piccirillo C (2020). Mussel shell-derived macroporous 3D Scaffold: Characterization and optimization study of a bioceramic from the circular economy. Marine Drugs 18: 309. DOI $10.3390 / \mathrm{md} 18060309$.

Shoushrah SH, Transfeld JL, Tonk CH, Büchner D, Witzleben S, Sieber MA, Schulze M, Tobiasch E (2021). Sinking our teeth in getting dental stem cells to clinics for bone regeneration. International Journal of Molecular Sciences 22: 6387. DOI 10.3390/ijms22126387.

Swartzlander MD, Blakney AK, Amer LD, Hankenson KD, Kyriakides TR, Bryant SJ (2015). Immunomodulation by mesenchymal stem cells combats the foreign body response to cell-laden synthetic hydrogels. Biomaterials 41: 79-88. DOI 10.1016/j.biomaterials.2014.11.020.

Vázquez A, Fernández-Sevilla LM, Jiménez E, Pérez-Cabrera D, Yañez R, Subiza JL, Varas A, Valencia J, Vicente A (2020). Involvement of mesenchymal stem cells in oral mucosal bacterial immunotherapy. Frontiers in Immunology 11: 567391. DOI 10.3389/fimmu.2020.567391.

Wang H, Cao Y (2019). WIF1 enhanced dentinogenic differentiation in stem cells from apical papilla. BMC Oral Health 19: 25. DOI 10.1186/s12903-018-0700-6.

Wang P, Sun Y, Shi X, Shen H, Ning H, Liu H (2020). Bioscaffolds embedded with regulatory modules for cell growth and tissue formation: A review. Bioactive Materials 6: 12831307. DOI 10.1016/j.bioactmat.2020.10.014.

Zhang F, Liang M, Zhao C, Fu Y, Yu S (2019). NFIC promotes the vitality and osteogenic differentiation of rat dental follicle cells. Journal of Molecular Histology 50: 471-482. DOI 10.1007/s10735-019-09841-z. 